\title{
Bao, Qinggang 暴慶剛, Reflection and Reconstruction: A Study of Guo Xiang's Commentary to the Zhuangzi 反思與 重構: 郭象《莊子註》研究
}

\section{Nanjing 南京: Nanjing Daxue Chubanshe 南京大學出版社, 2013, $3+4+377$ pages}

\section{Joanna Guzowska}

Published online: 9 October 2014

(C) The Author(s) 2014. This article is published with open access at Springerlink.com

This book is an extensive and systematic interpretation of GuO Xiang's 郭象 Commentary to the Zhuangzi 莊子註. It opens with an outline of GuO Xiang's biography and several textual issues surrounding his work, including the provenance and significance of the Foreword (Zhuangzi $x u$ 莊子序) and the plagiarism controversy (Chapter One). It continues with an overview of the historical and intellectual background of the period (Chapter Two). The core of the book (Chapters Three through Six) is devoted to an analysis and interpretation of GUO Xiang's project, both in comparison to and independently of the Zhuangzi text, and should be of particular interest to the philosophically minded reader. It is also the focus of the present review. Chapter Five, which I do not discuss in detail, is an overview of GuO Xiang's dual method of conceptual analysis (bianming xili 讋名析理) and interpretation via parable (jiyan chuyi 寄言出意). The book closes with an examination of the impact of the Commentary on later thought and its scholarly reception (Chapter Seven).

An undeniable merit of the book is that it is consistently woven around one central notion: ziyou 自由 (freedom) understood as xiaoyao 道遙 (unrestraint) in the sense of the Zhuangzi (96). The author develops his interpretation of the Commentary with tenacity and clarity which could be even greater if the term ziyou and the notion of xiaoyao were discussed more explicitly and in more detail earlier in the book.

Throughout the book Bao demonstrates that the fundamental goal of the Commentary is to reconcile, in one theory, two aspects of freedom: existential and political. More specifically, it is to offer an account of individual freedom compatible with the existence of an efficient political order on one hand, and to conceive of an order capable of facilitating the maximum of individual freedom, on the other. As Bao further specifies, the Commentary is best read in the context of the debate on the mutual relationship between the doctrine of names (institutional morality) (Mingjiao 名教) and

Joanna Guzowska $(\bowtie)$

Institute of Philosophy, University of Warsaw, Krakowskie Przedmieście 3, 00-047 Warsaw, Poland

e-mail: asia.guzowska@gmail.com 
the principle of self-so (spontaneity) (ziran 自然)—as an attempt to reconcile the two and thus to fuse Daoism and Confucianism.

Chapter Three of the book is an exposition of GuO Xiang's conception of freedom and revolves around Bao's core insight that there are two distinct notions of freedom in the Commentary: wudai xiaoyao 無待逍遙, the unbound freedom of the sage, which stems in part from the Zhuangzi; and shixing xiaoyao 適性逍遙, the nature-bound freedom of the myriad things, which is an innovation by GuO Xiang. The latter kind of freedom is predicated on the spontaneity of each thing's individual nature (xingfen 性 分): to be free in this sense is to live in accord with one's particular allotment (xing 性) and to keep within one's capacity zone (fen 分), which rather conveniently includes social role. The first kind of freedom, in contrast, is understood as an attitude specific to the sage where: (1) he entertains each thing in light of its individual nature and thus is able to tune into it without friction (xuanming 玄冥) (inner sage); and (2) he facilitates the actualization of nature-bound freedom in the myriad things through the policy of nonaction (wuwei 無為) (outer king) (107).

An interesting corollary to the discussion of GuO Xiang's conception of freedom is whether it should be read as an apology of the de facto regime. Bao answers in the negative and holds that the goal of the Commentary is to merge spontaneity and institutional morality on equal terms. In order to do that, Bao asserts, GuO Xiang establishes, in two steps, that the dichotomy is apparent: (1) that set norms are mere artefacts or traces ( $j i$ 跡) of the moral spontaneity of the sage, not morality per se; and (2) that the alienation of morality stems from an excessive emphasis on the first to the neglect of the latter. Much in the same vein, Bao argues that the apology view of GUO Xiang's thought derives from the conflation of two ideas of morality: actual (shiran 實 然, an artefact, the de facto system) and ideal (yingran 應然, the ideal system) (168). Guo Xiang's principal objective, according to Bao, is to rectify morality - to set it in motion so that it can keep in line with the changing reality of human nature (169).

Bao's defence is elegant and compelling in that it is itself very much in the style of the Commentary. However, Guo Xiang's idea of the inner sage and outer king as the facilitator of nature-bound freedom, and especially his incorporation of social role into the notion of individual nature, seem to cast doubt on this charitable interpretation. To be fair, Bao is not uncritical about it - he concurs that GuO Xiang's system hangs entirely on the sagacity of the ruler and thus remains "suspended between reality and an ideal" (194). And yet, the problem, as I understand it, goes deeper than that.

Guo Xiang's thought, as interpreted by Bao, shows affinity with the theme of an empty centre and full and productive periphery present in the Laozi and, appropriately reworked, in the Hanfeizi 韓非子. This points to an interesting circumstance not explored in the book: the persistence of Huang-Lao 黄老 and/or Legalist elements in political thought throughout and after the Han 漢, including Guo Xiang. Obvious references to Zhuangzian Daoism and Confucian ethics notwithstanding, the system developed in the Commentary, as interpreted by Bao, bears structural resemblance to that expounded in Legalism: an orderly social body facilitated by the single ruler who is qualitatively different from all else. Perhaps then, Guo Xiang's philosophy should be viewed as more complex than, if not different from, the somewhat cliché fusion of Daoism and Confucianism. Be that as it may, I think that Bao's dual framework captures GuO Xiang's conception of freedom rather well. 
Chapter Four is an analysis of what Bao refers to as the metaphysical foundation of Guo Xiang's project: duhua 獨化 (lone transformation), xingfen 性分 (individual nature), and ziran 自然 (self-so) (200). According to Bao, the three are inextricably interconnected and jointly serve to support the centrepiece of the Commentary: the notion of nature-bound freedom. The conception of individual nature makes it possible to objectively ground and to proliferate the possibility of freedom. The conception of lone transformation, in turn, is intended to provide rationale for the identification of freedom with adherence to one's individual nature. The notion of self-so, finally, further cements the system by stressing, over again, the fundamental idea that lone transformation, and thus each thing's individual self-determinacy, has no external source but is radically spontaneous: in and of itself and therefore free (276).

There are two subplots in Bao's discussion of Guo Xiang's metaphysics that deserve special attention. The first is the apparent paradox between the theory of lone transformation and the obvious fact of causal interdependence of individual things. In order to resolve the issue, Bao evokes the distinction found in the Commentary between the metaphysically benign notion of jinyin 近因, or close reliance (here xiangwei 相為, the mutual making of things, is an obvious by-product of their ziwei 自為, self-making [220]), and the metaphysically loaded notion of the ultimate cause. Only the latter is critiqued, deconstructed and rejected as self-contradictory in GuO Xiang. Whether Bao's exploration suffices to settle the issue of causality in GUO Xiang, and whether the issue can be satisfactorily settled at all, will likely depend on the conception of causality shared by the reader.

The second issue is the exact purport of the notion of individual nature in the Commentary. Bao observes, and aptly so, that GuO Xiang does not define it in clear terms and goes on to offer an intelligent guess based on indirect historical and textual evidence. His conclusion is that the notion in question is best understood in terms of an inborn $q i$ 氣-endowment imbued with specific potentiality. As such, individual nature is obtained once and for all - it cannot be changed, taken away from or added to (225 and also 265). (For an opposing view see Brook Ziporyn, Penumbra Unbound [Albany: SUNY Press, 2003]: 48-50.) Bao revisits the issue of individual nature in Chapter Six where he discusses the paradoxical character of this notion in GuO Xiang.

Chapter Six discusses select interpretive errors and/or conscious misreadings of the Zhuangzi on the part of GuO Xiang as well as several blind spots within the Commentary itself, regardless of the original material it comments on. There are two major areas of exploration here. The first regards the notion of lone transformation as an attempt to reject causal discourse in metaphysics. According to Bao, Guo Xiang merely glosses over the question of the first cause but does not solve it. This is due to the fact that the notion of generation implies the dichotomy of the generator and the generated, which renders the notion of self-generation impossible to establish (326). Bao further suggests that Guo Xiang may have realized it and surreptitiously reinstated the notion of the original source via the less apparent notion of xuanming zhi jing 玄冥 之境 (the dark field) (327-328). I do not find this particular set of objections convincing, nor do I consider the notion of self-generation any more intellectually suspect or in need of an explication than that of the original source that simply is.

The second, truly systemic, problem justly raised by Bao is the ubiquitous tension in the Commentary between what is formed a priori and what develops a posteriori, between potentiality and actuality or nature and nurture. GuO Xiang's individual nature, 
as interpreted by Bao, is obtained once and for all; at the same time, it is sheer potentiality in need of actualization. In light of this polarity, GuO Xiang's entire project appears as one giant philosophical balancing act between the stability of the given and change. As Bao remarks, each individual is perpetually in the making (and so is the historical process at large). Certainly, we can in each case assume an initial pool of talent, and even an implicit social role waiting to come to full bloom, and call it individual nature. However, we can only entertain it ex post, having observed the individual's entire life and thus, strictly speaking, when that individual no longer is (331).

Given this, individual nature, as scrutinized by Bao, turns out to be no more than an odd Ding an sich - something that can be postulated but that can have no informational impact on our decision-making. On the other hand, when we stress spontaneous change rather than prefixed nature (and thus approximate Ziporyn's reading), we are faced with another problem: in a world of pure spontaneity everything is perfectly on a par with everything else. Of course, this renders freedom universally attainable, if such is our idea of freedom, by which the existentialist end of GuO Xiang's project can be considered secured. However, this also cancels out normativity, the sine qua non condition of institutional morality, which threatens the political end of the system, including the figure of the sage - that great facilitator of nature-bound freedom in the myriad things. One way or another, the paradox remains.

These are by no means all the subplots and motifs explored in Bao's book. By way of an abrupt conclusion I may say that although I do not always agree with the authorand this extends onto his reading of the Zhuangzi which I have left undiscussed due to constraints of space-I find his book informative and philosophically engaging. An overall regret I have is that Bao does not question, from the perspective of the conceptual structure of the Commentary, the validity of the fusion view (Ru-Dao huitong 儒道會通) or explore the issue of how much (Zhuangzian) Daoism and (Classical) Confucianism there remains in Guo Xiang. This is too bad, especially since Bao's framework of dual freedom is well suited for the task.

Open Access This article is distributed under the terms of the Creative Commons Attribution License which permits any use, distribution, and reproduction in any medium, provided the original author(s) and the source are credited. 